\title{
Palatal Injection: A Myth or a Reality in Maxillary Third Molar Extraction
}

\author{
${ }^{1}$ Suraj Pawar, ${ }^{2}$ Rujuta Ajit Desai, ${ }^{3}$ Mukul Padhye, ${ }^{4}$ Vruturaj Shevale, ${ }^{5}$ Rishi Khosa \\ ${ }^{6}$ Ekta Keswani, ${ }^{7}$ Snehal Thakker, ${ }^{8}$ Vaibhav Shah
}

\begin{abstract}
Introduction: Palatal injection, in spite of many modernized injection techniques, remains a painful experience for the patient. The aim of this study was to demonstrate if maxillary third molars could be extracted using only buccal infiltration of $2 \%$ lignocaine hydrochloride $(\mathrm{HCl})$ with adrenaline $1: 80,000$ without the need for supplemental palatal injection.

Materials and methods: Three hundred patients were selected randomly and divided into two groups of 150 each. In the experimental group, $2 \mathrm{ml}$ of $2 \%$ lignocaine hydrochloride with 1:80000 adrenaline was injected into the buccal vestibule of the tooth to be extracted. Extraction was performed after a waiting period of 7 minutes postinjection. Equal number of 150 patients were used as control and were subjected to the same protocol, with additional palatal injection. Pain experienced during extraction of both groups were recorded using visual analog scale and faces pain scale. Mann-Whitney test was used to analyze pain between both the groups.
\end{abstract}

Results: Statistical analysis of the two groups, experimental and control groups do not defer with respect to visual analog and faces pain score.

Conclusion: Palatal injection for extraction of maxillary third molar is not mandatory.

Keywords: Palatal injection, Wisdom teeth, Exodontia.

How to cite this article: Pawar S, Desai RA, Padhye M, Shevale V, Khosa R, Keswani E, Thakker S, Shah V. Palatal Injection: A Myth or a Reality in Maxillary Third Molar Extraction. World J Dent 2014;5(1):28-32.

Source of support: Nil

Conflict of interest: None

\section{INTRODUCTION}

Exodontia is one of the important procedures carried out in general dentistry. In everyday practice, maxillary third molars are required to be extracted for various reasons, like orthodontic treatment, profound caries, apical pathologies,

\footnotetext{
$1,2,7,8$ Lecturer, ${ }^{3}$ Professor, ${ }^{4,6}$ Associate Professor, ${ }^{5}$ Associate Surgeon

1-4,6-8 Department of Oral and Maxillofacial Surgery, Dr DY Patil Dental College and Hospital, Navi Mumbai, Maharashtra, India

${ }^{5}$ Department of Oncology, Kokilaben Hospital, Mumbai Maharashtra, India

Corresponding Author: Suraj Pawar, Lecturer, Department of Oral and Maxillofacial Surgery, Dr DY Patil Dental College and Hospital, Nerul, Navi Mumbai, Maharashtra, India Phone: 9833542258, e-mail: suraj@drpawars.com
}

periodontitis and prophylactic reasons. The procedure in itself is well tolerated however the pain of palatal injection is well known and is also universally detailed in textbooks. ${ }^{1-4}$ This pain is due to the tight binding of the palatal mucosa to its underlying periosteum and its abundant nervous supply. ${ }^{5}$ Although a number of adjunctive techniques have been described to reduce the discomfort of palatal injection ${ }^{1,3,6}$ they are not cost effective and have not gained much acceptance. In spite of conventional teaching which indicates use of palatal injection prior to removal of maxillary molars, many in recent studies conducted state otherwise. ${ }^{5,7-9} \mathrm{ME}$ Badcock, ${ }^{7}$ Sina Uckan $^{5}$ in their studies provided evidence that poorly tolerated palatal injection for removal of maxillary molars may not be required. The above-mentioned studies have a smaller sample size of about 50 to 55 patients and have essentially studied a young adult group. Also these studies have used articaine as the local anesthetic which as claimed is able to diffuse hard and soft tissues reliably ${ }^{3}$ and therefore obviates the need for a palatal injection when infiltrated buccaly, when maxillary teeth are indicated for extraction. There is sparse literature with regards to $2 \%$ lignocaine hydrochloride $(\mathrm{HCl})$ and all these studies have demonstrated the need for further investigations.

Hence, the aim of our randomized study was to demonstrate that the need for poorly tolerated palatal injection using $2 \%$ lignocaine $\mathrm{HCl}$ is not mandatory for extraction of maxillary third molars as conventionally thought using a bigger sample size and a wider range in age group where we have included older patients also. This was done by comparing randomly selected 300 people which were divided into two equal groups . Experimental group of 150 people were given only buccal infiltration of lignocaine $\mathrm{HCl}$ and control group of 150 people were given buccal as well as palatal injection.

\section{MATERIALS AND METHODS}

The study was carried out in our department over the period of 4 months. Permission to carry out the study was taken from ethical committee of the hospital, and informed consent was taken from all patients. Three hundred patients who required maxillary third molar extraction were randomly selected. Medically compromised patients were not included in the study. 
They were divided into two groups: experimental and control groups, equally to eliminate bias. Control group received the conventional buccal infiltration followed by palatal injection. Experimental group received buccal infiltration only. Lignocaine $\mathrm{HCl}$ with 1:80000 adrenaline was used in standard $2 \mathrm{ml}$ syringes. $1.5 \mathrm{ml}$ was injected in buccal sulcus in both the groups. 0.4 to $0.5 \mathrm{ml}$ of anesthetic solution was infiltrated in palate in the control group. After an interval of 7 minutes to allow for the anesthetic effect, teeth were extracted using buccal manipulation only with straight coupland elevator. Only erupted maxillary molars were extracted in our study. No suturing was done.

If an unacceptable level of pain or discomfort was experienced during extraction a further $2 \mathrm{ml}$ of lignocaine $2 \%$ with adrenaline was injected initially as a second maxillary buccal infiltration and if the pain still persisted palatal injection was administered and recorded. Our study included provision to abort the trial if greater than $10 \%$ of patients required palatal injections for comfortable extraction.

Pain experienced during extraction for both groups were recorded using visual analog scale (VAS) and faces pain scale (FPS). For VAS zero was considered as no pain and 10 being maximum pain. In case of FPS zero was recorded as no pain and 5 as maximum imaginable pain. FPS score was assessed from patients facial countenance by a single operator to avoid bias and VAS scale was recorded by the patient themselves after careful explanation about the scoring to the patient. The results were analyzed using statistical package for social sciences, SPSS version 15.0.

Descriptive statistics, like standard deviation and frequency, were calculated for age and gender. MannWhitney test was used to analyze pain between both groups. p-value of less than 0.05 was considered significant.

\section{RESULTS}

Three hundred patients took part in this study. Out of 150 patients in the experimental group, 74 were females and 76 were males and, out of 150 patients in the control group, 72 were females and 78 were males. In both the groups, minimum age was 17 and maximum age around 73 .

Frequency and percentage of VAS and FPS for better understanding is given in Table 1.

According to the VAS scale, three patients experienced severe pain in the experimental group that is the group where palatal injection was not given of the total 150 patients and these patients required second buccal infiltration. Fifteen patients experienced slightly more pain than the control group but whether these results were statistically significant was checked by Mann-Whitney test. According to statistical analysis, there is one independent variable, i.e. the groups
Table 1: Frequency and percentage of VAS and FPS

\begin{tabular}{|c|c|c|c|c|}
\hline \multicolumn{5}{|l|}{ VAS } \\
\hline Group & & & Frequency & Percentage \\
\hline \multirow[t]{7}{*}{ Experimental } & Valid & 1 & 30 & 20.00 \\
\hline & & 2 & 34 & 22.67 \\
\hline & & 3 & 38 & 25.33 \\
\hline & & 4 & 22 & 14.67 \\
\hline & & 5 & 22 & 14.67 \\
\hline & & 6 & 4 & 2.67 \\
\hline & & Total & 150 & 100.00 \\
\hline \multirow[t]{7}{*}{ Control } & Valid & 1 & 35 & 23.33 \\
\hline & & 2 & 34 & 22.67 \\
\hline & & 3 & 45 & 30.00 \\
\hline & & 4 & 18 & 12.00 \\
\hline & & 5 & 15 & 10.00 \\
\hline & & 6 & 3 & 2.00 \\
\hline & & Total & 150 & 100.00 \\
\hline \multicolumn{5}{|l|}{ FPS } \\
\hline Group & & & Frequency & Percentage \\
\hline \multirow[t]{6}{*}{ Experimental } & Valid & 1 & 42 & 28.00 \\
\hline & & 2 & 66 & 44.00 \\
\hline & & 3 & 27 & 18.00 \\
\hline & & 4 & 11 & 7.33 \\
\hline & & 5 & 4 & 2.67 \\
\hline & & Total & 150 & 100.00 \\
\hline \multirow[t]{6}{*}{ Control } & Valid & 1 & 39 & 26.00 \\
\hline & & 2 & 72 & 48.00 \\
\hline & & 3 & 24 & 16.00 \\
\hline & & 4 & 13 & 8.67 \\
\hline & & 5 & 2 & 1.33 \\
\hline & & Total & 150 & 100.00 \\
\hline
\end{tabular}

with two levels experimental and control and two dependent variables, i.e. the VAS and FPS. We had to analyze whether the group levels differ significantly from each other in term of VAS or FPS.

Since the dependent measure is of ordinal type and a discontinuous measure, the comparisons between levels could be made using a nonparametric test. Alternative of t-test of independent samples is the Mann-Whitney test.

\section{Descriptive Statistics for Tensile Stress of Different Groups}

The descriptive data presented in Table 2 shows that the maximum VAS score for the experimental group (6) is higher than that for the control group (5). Likewise the P25, P50 and P75 scores are all higher for experimental group by one than those for the control group. This is presented graphically in Graph 1. The Box Plot shows the difference in the higher end distribution of the VAS scores for the two groups. 
Table 2: Descriptive statistics for the two groups on two variables

\begin{tabular}{llllllll}
\hline Variables & Groups & $N$ & Min & Max & $P 25$ & $\begin{array}{l}\text { P50 } \\
\text { (median) }\end{array}$ & P75 \\
\hline VAS & Experimental & 150 & 1 & 6 & 2 & 3 & 4 \\
& Control & 150 & 1 & 5 & 1 & 2 & 3 \\
FPS & Experimental & 150 & 1 & 6 & 2 & 3 & 3 \\
& Control & 150 & 1 & 5 & 1 & 2 & 3 \\
\hline
\end{tabular}

Table 3: Results of the Mann-Whitney test on two variables for comparisons between two groups

\begin{tabular}{lllllll}
\hline Variables & Groups & $N$ & Mean rank & \multicolumn{3}{c}{ Mann-Whitney results } \\
\cline { 5 - 7 } & & & & u-value & z-value & $p$-value \\
\hline VAS & Experimental & 150 & 156.43 & 10361 & -1.21 & 0.225 \\
& Control & 150 & 144.57 & & & \\
\multirow{2}{*}{ FPS } & Experimental & 150 & 150.45 & 11242.5 & -0.01 & 0.991 \\
& Control & 150 & 150.55 & & & \\
\hline
\end{tabular}

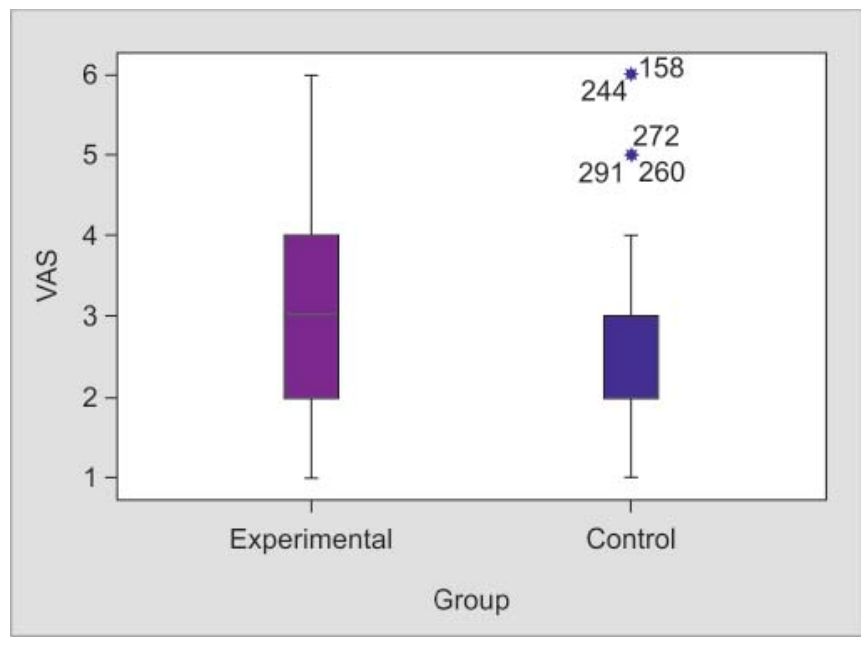

Graph 1: Box plot of VAS scores for experimental and control groups

There are five outliers at the upper end distribution of VAS scores for the control group. Thus very few patients in the control group have VAS score more than 4 . Whether these differences in the two distributions are statistically significant was checked by using Mann-Whitney test. The results of Mann-Whitney test are presented in Table 3.

The values of Mann-Whitney test associated with the data presented in Table 3 for VAS indicate that the mean rank for the experimental groups is higher compared to that for control. However, the Mann-Whitney u-value is not statistically significant (Mann-Whitney $\mathrm{u}=10361$, $\mathrm{z}=-1.21, \mathrm{p}=0.225)$. Thus, the distribution of VAS scores is not different between two groups.

The FPS scale which is recorded by the operator on basis of facial expression of the patient did not show much difference between the two groups though it also recorded severe pain felt by four patients of 150 in experimental group.

The descriptive statistics presented for the FPS scores in Table 2 reveal that the maximum, P25 and P50 scores

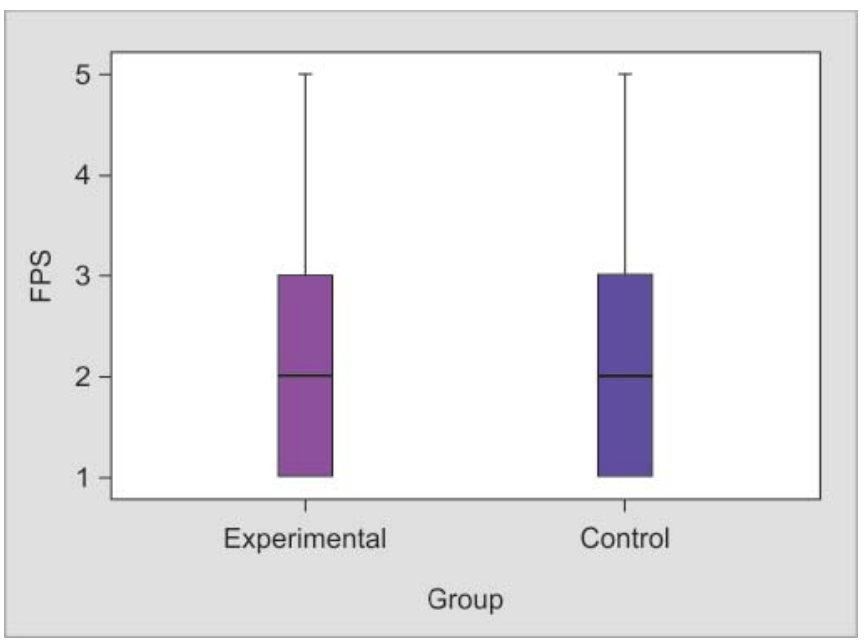

Graph 2: Box plot for FPS scores for experimental and control groups

are higher for experimental group by one than that for the control group respectively. The differences in the two groups' distributions on FPS are presented in Graph 2.

The two boxplots show major overlap and the differences are unlikely to be statistically significant. The associated results of the Mann-Whitney are not statistically significant (Mann-Whitney $\mathrm{u}=11242.5, \mathrm{z}=-0.01, \mathrm{p}=0.991$ ). Therefore, it can be concluded that the two groups do not differ with respect to the distributions on FPS.

In general, the data shows that experimental and control groups do not differ with respect to the VAS and FPS scores.

The study was designed so that if greater than $10 \%$ patients in experimental group reported a level of discomfort requiring palatal injection, the study would abort. This did not occur. No patients required palatal injection in the experimental group.

\section{DISCUSSION}

Results of the randomized clinical trial clearly demonstrate that palatal injection is not mandatory for maxillary third 
molar extraction. Badcock $\mathrm{ME}^{7} \mathrm{et}$ al and Sina ${ }^{5} \mathrm{et}$ al in their study in 2006 and 2007 respectively, also gave similar results. Although a more definitive conclusion could have been made by Badcock ME et al, if lignocaine had been compared to no injection like in our study instead in that study normal saline administration was included as placebo and also study was conducted on only 51 patients requiring bilateral maxillary third molar removal. In our study, we had 300 patients who required unilateral maxillary molar extraction with equal distribution in experimental and control groups to compare with. Hence, 150 patients underwent extraction without palatal injection.

Sina Uckan $^{5}$ et al also conducted a similar study but in his study he used articaine $\mathrm{HCl}$ as the anesthetic. Lima ${ }^{10}$ et al proved that maxillary third molar extraction could be performed with only $4 \%$ articaine $\mathrm{HCl}$ buccal infiltrative anesthesia in majority of cases with no need for supplemental palatal injection. Fan ${ }^{9}$ et al determined that depositing $1.7 \mathrm{ml}$ of $4 \%$ articaine $\mathrm{HCl}$ with 1:100,000 epinephrine into buccal vestibule provides similar clinical efficacy as routine type of anesthesia with palatal injection injection for maxillary tooth removal. But contrary, in a study conducted by Ozec ${ }^{11}$ et al, they could not find any evidence to confirm the hypothesis regarding vestibule palatal diffusion of articaine. The result of this study contradicts the results of the previous studies on this topic which advocated presences of vestibule palatal diffusion. In a comparative study between articaine and lidocaine, superiority of articaine over lidocaine could not be corroborated. Both solute presented similar behavior and both were not entirely efficient in controlling pain during treatment of irreversible pulpitis, which reveals their similar properties. ${ }^{12}$ In present study, deposition of lidocaine $\mathrm{HCl}$ to the buccal vestibule and 7 minutes latency period reveals statistical results as that of previous studies done using articaine. Raja Shekar $G^{8}$ et al also had similar results in 2011 but their study in particular was preliminary in nature, sample size of the study was small and had an unequal distribution between the control and experimental groups unlike our study.

While according to classical knowledge, 2 to 3 minutes delay will be sufficient in buccal infiltration anesthesia. ${ }^{2}$ A prolonged delay is necessary in this technique to allow diffusion of the solution on the palatal side. Similar observation was made by $\mathrm{Uckan}^{5}$ that palatal tissue are anesthetized sufficiently for extraction as a consequence of diffusion from buccal infiltration with a protracted latency period. In our study, the delay observed was for 7 minutes after the buccal infiltration. Majority of the patients described extraction as completely painless or very slight faint pain. However, it should be noted that palatal mucosa was not reflected or probed in any of the cases.
Number of techniques ${ }^{1,3,6,13-15}$ have been mentioned in literature to reduce discomfort of intraoral injections, such as application of topical anesthetic gel/spray, EMLA and TENS. EMLA has been used effectively intraorally; however, it is not designed for intraoral administration, and so contains no flavouring agent and is bitter tasting. ${ }^{13,14}$ Similarly, TENS has been advocated as a means of alleviating the pain of intraoral injections ${ }^{15}$ : however, a survey conducted in Australia and New Zealand regarding oral maxillofacial surgeons giving palatal injections or not, showed that majority (77 of the 84) surgeons who responded to the survey, 'always' gave palatal injection for extraction of maxillary third molars. ${ }^{16}$ No other such survey has been published internationally but it is common practice among clinicians to use conventional methods for maxillary extraction. Our study was therefore also conducted to bring about awareness among practitioners that discomfort to the patient could be avoided by simply modifying the existing technique with avoidance of palatal injection.

Also, there are still relatively few studies that strongly substantiate that palatal injection is not required for maxillary molar extraction after buccal infiltration with $2 \%$ lignocaine. However, the result of this study indicates lignocaine has indeed some vestibule palatal diffusion and that, in most cases, supplemental palatal injection is not necessary with prolonged latency period.

\section{CONCLUSION}

Palatal anesthesia can be provided in maxillary third molars with buccal infiltration of lignocaine $\mathrm{HCl}$ after a latency period of 7 minutes without the need for second palatal injection. Therefore, we can conclude that palatal injections are not mandatory for extraction of erupted maxillary third molars.

A multicenter research on all maxillary teeth with more than one operator at a larger scale is required to remove bias and to create awareness among dental practitioners.

\section{REFERENCES}

1. Aslin WR. Reduced discomfort during palatal injection. J Am Dent Assoc 2001;132:1277.

2. Malamed SF. Handbook of local anesthesia. 5th ed. Mosby. 2004. p. 202-213.

3. McArdle BF. Painless palatal anesthesia. J Am Dent Assoc 1997;128:647.

4. Meechan JG. Effective topical anesthetic agents and techniques. Dent Clin North AM 2002;46:759-766.

5. Uckan S, Dayangac E, Araz K. Is permanent maxillary tooth removal without palatal injection possible? Oral Surg Oral Med Oral Pathol Oral Radiol Endod 2006;102:733-735.

6. Duncan JD, Reeves GW, Fitchie JG. 'Technique to diminish discomfort from the palatal injection'. The Journal of Prosthetic Dentistry, 1992;67(6):901-902. 
7. Badcock ME, Gordon I, McCullough MJ. A blinded randomized controlled trial comparing lignocaine and placebo administration to the palate for removal of maxillary third molars. Int J Oral Maxillofac Surg 2007;36:1177-1182.

8. Raja Sekhar G, Nagaraju T, et al. Is palatal injection mandatory prior to extraction of permanent maxillary tooth: a preliminary study. 2011;22(1):100-102.

9. Fan S, Chen WL, Yang ZH, Huang ZQ. Comparison of the efficiencies of permanent maxillary tooth removal performed with single buccal infiltration versus routine buccal and palatal injection. Oral Surgery, Oral Medicine, Oral Pathology, Oral Radiology and Endodontology 2009;107(3):359-363.

10. Lima-Júnior JL, Dias-Ribeiro E, de Araújo TN, Ferreira-Rocha J, Honfi-Júnior ES, Sarmento CF, et al. Evaluation of the buccal vestibule-palatal diffusion of $4 \%$ articaine hydrochloride in impacted maxillary third molar extractions. Med Oral Patol Oral Cir Bucal 2009;14:E129-132.
11. Ozeç I, Tasdemir U, Gumus C, Solak O. Is it possible to anesthetize palatal tissues with buccal $4 \%$ articaine injection? J Oral Maxillofac Surg 2010;68(5):1032-1037.

12. Tortamano IP, Siviero M, Costa CG, Buscariolo IA, Armonia PL. A comparison of the anesthetic efficacy of articaine and lidocaine in patients with irreversible pulpitis. J Endod 2009;35:165-168.

13. Bernardi M, Secco F, Benech A. Anesthetic efficacy of a eutectic mixture of lidocaine and prilocaine on the oral mucosa: prospective double blind study with a placebo. Minerva Stomatal 1999;48:39-43.

14. Munshi AK, Hedge AM, Latha R. Use of EMLA: Is it an injection free alternative? J Clin Pedatr Dent 2001;25:215-219.

15. Quarnstorm F. Electronic Dental Anesthesia. Anesth Prog 1992;39:162-177.

16. Badcock ME, McCullough MJ. Palatal anaesthesia for the removal of maxillary third molars as practised by oral and maxillofacial surgeons in Australia and New Zealand. Aust Dent J 2007;52:329-332. 